\title{
Good learning = A Good Life: Mathematics Transformation in Remote Indigenous Communities
}

\author{
Robyn Jorgensen (Zevenbergen), Peter Grootenboer, Peter Sullivan
}

\begin{abstract}
The performance of Australian Indigenous ${ }^{1}$ learners is a national concern. The federal government has recognised that health and education are keys to closing the gap between the achievement of Indigenous and non-Indigenous people and has made health and education a national priority. Through its 'Closing the Gap' initiative, the Rudd government is allocating significant amounts of money to redress the poor health and education among Indigenous Australians. In this paper, we discuss an innovation in education that is being implemented in a cluster of remote communities in Western Australia. ${ }^{2}$ The innovation draws on international research that has positively affected mathematics learning, particularly among students who are traditionally excluded from formal schooling. While the research is innovative, the mechanisms that may be the most effectual in bringing about strong mathematical learning for Indigenous Australians are unknown.
\end{abstract}

Keywords: Indigenous students, Mathematics learning, creating opportunity

\footnotetext{
${ }^{1}$ We recognise the problematic nature of using a totalising term such as Indigenous Australians as it fails to recognise the diversity of cultures within this term. We use it as shorthand to refer to the diverse Indigenous cultures of Australian Aboriginal and Torres Strait Islander people.

2 This project is funded by the Australian Research Council through its Linkage Grants Scheme. The Industry Partner is the Association of Independent Schools of Western Australia.
} 


\section{Introduction}

National testing across Australia is undertaken in Years 3, 5, 7, and 9. As the time at which children start school and the number of years of schooling vary across states, comparisons across the states are somewhat flawed. However, there are general trends that can be observed in the test data. Of concern for us is the difference in performance between Indigenous and non-Indigenous learners. The data in Table 1 from the 2008 tests (MCEETYA 2009) indicate a number of key outcomes. In all cases, Indigenous students perform at a lower level than do non-Indigenous learners. Of even more concern is that in some states and territories, the scores of Indigenous students are considerably different from those of non-Indigenous students. For example, in the Northern Territory, only $50 \%$ of Indigenous students reach benchmarks in comparison with more than $90 \%$ of non-Indigenous students. While this is the worst performance from all the jurisdictions, other states have similarly concerning data. In considering these data, one must also consider the issue of geolocation. In those states where performance differences are greater than $20 \%$, considerable numbers of Indigenous students live in remote locations. Thus, issues of remoteness compound the factors that affect learning.

Table 1:Percentage of Students Meeting Numeracy Benchmark by State

\begin{tabular}{llllllllll}
\hline State/Territory & Indigenous Status & Yr 3 & diff & Yr 5 & diff & Yr 7 & diff & Yr 9 & diff \\
\hline NSW & Indigenous & 88.6 & & 78.9 & & 84.5 & & 80.3 \\
\hline VIC & Non-Indigenous & 97.3 & 8.7 & 95.2 & 16.3 & 96.6 & 12.1 & 95.4 & 15.1 \\
\hline & Indigenous & 93 & & 83.3 & & 87.9 & & 78.4 & 17.1 \\
\hline QLD & Non-Indigenous & 96.8 & 3.8 & 95 & 11.7 & 96.8 & 8.9 & 95.5 & 17 \\
\hline WA & Indigenous & 75.5 & & 69.5 & & 81.8 & & 73.2 & \\
\hline & Non-Indigenous & 93.3 & 17.8 & 92 & 22.5 & 95.9 & 14.1 & 93.8 & 20.6 \\
\hline SA & Indigenous & 75.5 & & 61.6 & & 74.2 & & 66.2 & \\
\hline NAS & Non-Indigenous & 96.1 & 20.6 & 93.7 & 32.1 & 96.5 & 22.3 & 94.3 & 28.1 \\
\hline & Indigenous & 79.2 & & 68.5 & & 75.9 & & 68.7 & \\
\hline ACT & Non-Indigenous & 94.6 & 15.4 & 91.7 & 23.2 & 95.4 & 19.5 & 93.7 & 25 \\
\hline & Indigenous & 94.5 & & 87.8 & & 92.4 & & 88.5 & \\
\hline NT & Non-Indigenous & 96.8 & 2.3 & 92.9 & 5.1 & 95.5 & 3.1 & 93.1 & 4.6 \\
\hline & Indigenous & 88.4 & & 82.3 & & 90.3 & & 83.8 & \\
\hline AUST & Non-Indigenous & 96.7 & 8.3 & 95.3 & 2.4 & 97.3 & 7 & 96.9 & 13.1 \\
\hline & Indigenous & 52.4 & & 38.3 & & 50.2 & & 46.1 & 93.6 \\
\hline Non-Indigenous & 96.5 & 44.1 & 91.6 & 53.3 & 95.6 & 45.4 & 93.5 \\
\hline
\end{tabular}

Note. From National Assessment Program Literacy and Numeracy: Achievement in reading, writing, language conventions and numeracy, by MCEETYA, 2009, Canberra: MCEETYA. Copyright 2009 by MCEETYA.

Of primary concern here is the achievement of Indigenous students in learning mathematics. This focus is not intended to diminish the importance of other areas of learning, including literacy and health. However, as Lamb (1997) 
has convincingly shown, performance in numeracy at Year 10 is the strongest indicator of life chances. Within this context, the poor performance of remote Indigenous students becomes even more significant.

In this paper we provide an overview of a 3-year intervention study and discuss the implementation of the project in a remote area of Australia ${ }^{3}$. Six Aboriginal community schools are participating in the study. The schools vary in size, ranging from a one-teacher school through to one school that has six classes. Similarly, the leadership at each school is quite different, as are the ways in which local people (i.e., Indigenous workers) are incorporated into the school staff. The teaching staff (i.e., trained and registered teachers) in all of the schools are generally very young; many of the teachers are in their first or second year of teaching. There is a considerable turnover of staff with the expectation that teachers remain in the school for two years, but this is not always the case. The youthfulness of the teachers is both a strength and weakness for the communities, because the teachers' exuberance and enthusiasm can counteract their lack of experience. However, the remoteness of the region and the isolation of each school mean that professional development and linking with other schools is often difficult.

\section{The Research Project}

Drawing on international literature that reports on initiatives that have been successful in redressing educational disadvantage for marginalised learners, the project team developed a pedagogical model that employed effective practices for learning mathematics. However, the project team acknowledges the uniqueness of Indigenous learners in this context, and thus sees the early years of the project as a design research study (Cobb, Confrey, diSessa, Lehrer, $\&$ Schauble 2003). At this point in the study, those aspects that work well (or not) with Indigenous learners are a key aspect of the project and are still being researched. These are discussed later in this paper.

\section{Background to the Communities}

The schools involved in the study form a cluster in a very remote region of Australia. The most convenient meeting point for the six schools is 450 $\mathrm{km}$ from a regional airport. Many of the schools are situated hundreds of kilometres from this area. Some schools are approximately $100 \mathrm{~km}$ off the main highway along dirt tracks. Some communities have deliberately chosen to be in such remote conditions so that they can isolate themselves from Western communities and associated problems (usually intertribal issues, alcohol, social problems, pay back). Most of the communities can be accessed only via four-wheel drive. In the wet season, many, if not all of the schools may be isolated for a month or more as inbound roads are cut by swollen rivers. For this project, issues of isolation and remoteness are foregrounded.

\footnotetext{
${ }^{3}$ Further details of the study can be found in Zevenbergen \& Niesche (2008) and Jorgensen, Grootenboer \& Niesche (2009).
} 
In these communities, the Aboriginal people have their own Council and are empowered to make decisions that reflect the views of the community as well as providing governance of that community, including the school. The Council is actively involved in the selection of school staff and this task is usually undertaken in consultation with the principal and other staff. Regular meetings are held with the Council, and the principal is a participant in the meetings. Other teachers may also be involved in the Council. Access to the schools and communities is subject to the Council approving such involvement.

\section{The Project}

The project draws heavily on the outcomes of Boaler's (2008) study of Railside. Railside was a Californian school that progressed from being the lowest performing school in the state to achieving above average results in a few years, through the implementation of 'complex instruction' (Cohen \& Latan 1997). While this school served one of the most impoverished and socially diverse communities in California, the principles upon which it was developed were seen to offer insights into the pedagogies that may work for Indigenous learners. At the same time, the work of Sullivan, Mousley and Zevenbergen (2006) has informed the project in terms of the inclusion of learners in teacher planning. Drawing on these projects and other research, we have developed a transformative approach to mathematics teaching and learning. For the first two years the project sought to implement and evaluate aspects of these pedagogies to ascertain their effectiveness in remote Indigenous contexts.

The project aims to shift pedagogy from a traditional approach to a more inclusive approach which has proved successful in other disadvantages communities (e.g., Boaler \& Staples 2008). We focus on two key beliefs that underpin this shift. The first is that teachers must have high expectations of learners; the second is that the mathematics learning must be deep and rich. These beliefs challenge much of what is undertaken in deficit models evident in mathematics education (Zevenbergen 2003). Successful work has been undertaken in literacy (Gray 1999) in communities that have adopted the principles of high expectations and deep learning. This work realises that appropriate scaffolding of Indigenous learners is key to their literacy successes. Gray has convincingly shown that quality learning with high outcomes is possible and that offering an impoverished curriculum disadvantages Indigenous learners.

\section{Table 2:Shifts in Pedagogy}

\begin{tabular}{ll}
\hline Traditional Pedagogy & Inclusive Pedagogy \\
\hline Teacher directed & Student centred \\
Individual & Group work \\
Text based & Activity, problem based \\
Ability grouping & Heterogeneous grouping \\
Hierarchical, linear, lock-step & Networked learning \\
Competitive & Collaborative \\
Correction of work & Reporting back \\
Assessment of learning & Assessment for learning \\
\hline
\end{tabular}




\section{Inclusive Pedagogy}

We have adopted the term 'inclusive pedagogy' to refer to the combination of strategies that have been found to be successful across a range of studies (e.g., Boaler \& Staples 2008). We are investigating the effectiveness and practicality of these pedagogies in these remote community schools. The inclusive pedagogy model is drawn from a number of key international research projects that have been shown to positively affect learning for disadvantaged students. However, the model has not been trialled in Indigenous communities so it is unclear as to what, if any, of the approaches would offer potential for Aboriginal and/or Torres Strait Islander Australians. We are only able to comment on Aboriginal people living in the Kimberley region as this is where these data have been collected. In the following sections, we outline the pedagogical reform that is the basis of this project.

\section{Tasks with High-Demand Mathematics}

Often there is a tendency to reduce the demand of learners who may appear to be struggling with mathematics. In the Railside study, one of the key features was the use of activities that were mathematically demanding. Similarly, studies on ability grouping have shown consistently that when the lower level groups are put together, they are frequently given an impoverished curriculum and locked out of progressing to more complex mathematics (Boaler, William, \& Brown 2000; Gamoran 1992). The more complex mathematics that is offered to the students in the higher streamed classes is in the form of tasks that are mathematically strong and contextually rich. The context of these tasks can be both social and cultural. However, this approach requires that the teachers come to understand the remote context and to learn about the backgrounds and lifestyles of the students.

\section{Group Work}

The adage that the group is greater than the sum of the individuals has been adopted in this project. We assume that grouping students in heterogeneous groups provides opportunities for learners to support each other. These opportunities take the onus off the teacher and move responsibility to the group. In line with a collective responsibility philosophy, there is no concept of a student failing or being left behind, and it is the role of the group to ensure that everyone is able to understand the work required. Moreover, it is envisaged that group work will be consistent with the communal lifestyle of these Aboriginal communities, but we are cognisant that this pedagogical approach is not well understood in this context at this stage.

The group members have specific roles that collectively are aimed at ensuring that all understand the concepts that are the focus of the lesson/activity. The complex instruction model also requires group accountability. This means that the group works collectively on the problem and that the members work with their peers to ensure that they all understand. When the task is completed and all members can verbalise the deep learning central to the task, the group leader summons the teacher to the group. The teacher then selects a member 
or two and pose questions to them. If the student is unable to respond in an appropriate manner, the teacher moves away from the group and requests that the members help the student to understand the mathematics.

\section{Use of Home Language}

Research on multilingual learners and code switching has highlighted the cognitive demands learners experience when they have to switch between languages (Setati \& Adler 2001). In the Railside study (Boaler \& Staples 2008), students were able to use their home language in their small groups to negotiate meaning. This approach reduces the cognitive load demanded in switching and translating between languages, and thus frees cognition and interaction to enable greater possibilities for meaning making. This is a particularly important issue in the Kimberley context.

\section{High Interactivity}

The work of Burton (2004) with research mathematicians has highlighted the disjunctions between the ways of working in mathematics classrooms (solitary, competitive, low interaction) and ways of working in research mathematics. Burton reported that there was, among other things, considerable interaction among mathematicians as they worked collectively to solve complex problems. She found that they would also simplify the variables, draw on their present knowledge, and then expand this to find new solutions. Interestingly, Burton's findings highlighted the misconceptions many teachers have of mathematical practice. In particular, she stressed the significance of interaction in mathematical practice, and the importance of interaction in learning mathematics. We are examining the best ways for this approach to be facilitated, with a particular focus on quality group work.

\section{Reporting Back}

At the end of an investigation, students report back in their groups. This process helps to promote metacognition as well as the development of a strong mathematical language. The reporting back focuses not only on the solution, but also the solution paths, stumbling blocks, resolution of difficulties encountered, and so forth. In the context of multilingual classrooms, this phase compels students to use Standard Australian English and this is critical for their language competency in communicating in the dominant language - a critical life skill for Indigenous learners. We are encouraging teachers to explore ways of effectively promoting reporting back in Standard Australian English.

\section{Assessment for Learning}

Typically assessment in mathematics identifies what students do not know rather than what they do know. This process is not as informative for teaching as it could be, because it does not enable the teacher to identify what is known and where to take the learner next. As Gray's (1999) work in literacy has shown, scaffolding learning is critical if students are to progress. To be effective in scaffolding, and thus to extend students' zone of proximal development, teachers must have knowledge of students' current understanding (Goos 2005). The extensive work of William and colleagues (Harrison, Black, \& 
Wiliam 2004) has shown the value of assessment when used to inform learning strategies. This assessment includes the on-going assessment of the teachers, the use of an on-line assessment tools used by the schools, and other occasional data collection.

\section{Multiple Entry Points and Multiple Pathways}

An approach is needed that caters for the wide range of understandings with which learners enter their mathematics classrooms. This diversity establishes a need for rich mathematical tasks that cater for students with different levels of previous mathematical achievement and interest, and a variety of ways of thinking, learning, and working mathematically. Such activities with multiple entry points and multiple solution pathways not only cater for a range of students, but also enhance the intellectual quality of the learning because students are required to consider and evaluate alternative views and ideas that are presented in their group.

\section{Productive Pedagogies}

One set of data comes from examining video records of teacher practice. We are using a modified version of the productive pedagogies model of practice, which has been adopted in various forms across most states of Australia. Originating in Queensland and used as the basis for the Queensland Study Longitudinal Reform Study (QSLRS) (Education Queensland 2001), it consists of four dimensions with 20 items (Table 3). The four dimensions focus on the intellectual and social features of the pedagogy. The framework organises pedagogy into clearly identifiable features and provides a strong language of description. One of the findings of this study was that teachers were generally strong on providing a supportive learning environment but less successful in the provision of an intellectually rigorous environment. The dimensions of this framework are summarised in Table 3, but described in more detail elsewhere (Lingard, Mills, \& Hayes 2006).

Table 3:Productive Pedagogies Framework

\begin{tabular}{ll}
\hline Intellectual Quality & Connectedness \\
\hline Higher order thinking & Knowledge integration \\
Deep knowledge & Background knowledge \\
Deep understanding & Deep understanding \\
Substantive conversation & Connectedness to the world \\
Knowledge as problematic & Problem-based curriculum \\
Metalanguage & \\
\hline Supportive School Environment & Recognition of Difference \\
\hline Student direction & Cultural knowledges \\
Social support & Inclusivity \\
Academic engagement & Narrative \\
Explicit performance criteria & Group Identity \\
Self regulation & Active citizenship \\
\hline
\end{tabular}


For this project the authors are analysing videos of lessons using the QSLRS method and hope to see a growth in the scores over time (for more details see Zevenbergen, Niesche, Grootenboer, \& Boaler 2008). Baseline data collected in 2008 suggests a positive change from the start of the project.

\section{Change over Time}

Over the three years of this study, we have been observing changes in the data for the teachers through the tracking of scores on the inclusive pedagogy video analysis. At least three reviewers examine the video (or classroom setting) and at the end of the teaching session score the lesson. Scores can range from 1 (indicating that the pedagogical aspect was not evident) through to 5 (indicating that the pedagogical aspect was a significant and integral part of the lesson). Each reviewer individually scores the lesson, and once all scores had been completed, the group of viewers negotiates an agreed score. It is not a process of creating a mean score but one in which the reviewers must argue for the scores they have given and then derive the agreed score. This process has been found to be a rigorous one in which potential differences in interpretation of criteria must be negotiated and agreed upon. This process has been successfully employed previously by researchers in the project team in a number of studies examining teaching practice (Lerman \& Zevenbergen, 2006; Zevenbergen \& Lerman 2008).

We examined 16 videos near the start of the project in 2008 and 16 more towards the end of 2009. We noticed an upward trend in scores overall but with some areas not progressing. It is not our intention in this paper to focus on the scores as the sample is too small for any statistical analysis to be undertaken. However, these trends both support and challenge the inclusive pedagogy model.

Overall, there has been a strong increase in the scores on the inclusive pedagogy framework. This suggests that the approach has positively influenced the teachers' pedagogy to make for more rigorous learning environments with quality and deep learning opportunities. The mean scores for the video data have risen from 1.97 at the start of the project to 2.51 at the end of 2009 with the scores increasing in each domain to a greater or lesser extent. In the remainder of this paper, we discuss the pedagogical aspects that have changed and those that have remained constant. We draw on interviews with the teachers, classroom observations, and field notes from our visits to the schools ${ }^{4}$ that help to explain why some of these dimensions may be problematic for remote Aboriginal learners.

\section{High Mathematical Demands}

Overall, there has been a shift in the mathematical demands of the tasks being employed by the teachers (mean video scores rose from 2.13 to 3.56). They have shifted from a predominately rote and drill learning approach, to using

\footnotetext{
${ }^{4}$ For greater detail on the research design see Jorgensen, Grootenboer, \& Niesche (2009)
} 
more tasks that are rich and somewhat complex (relative to the age of the learners). This has been a strong change in the teachers' practice as they have come to see that the students are capable of learning complex mathematics with appropriate scaffolding. For the participating teachers, there has been a strong shift from deficit, low level thinking of learners to a view that sees Aboriginal learners as capable and confident. The shift we have observed here may be explained by the emphasis we have placed on scaffolding the teachers and the provision of materials to support the high demand in mathematical tasks.

\section{Multiple Pathways and Entry Points}

Aligned with the organisation of mathematical tasks, the teachers have taken on board the use of open-ended questions to provide a multidimensional activity that enables learners to enter at various points. This finding has been a consistent one in the project and teachers have found it to be valuable given the diversity within any classroom. The classrooms are often multi-age and in some cases up to four different age groups may be in one class. Further compounding the challenges of the age range are attendance rates: some students may be regular attendees while others may have missed considerable time at school or been itinerant. This makes teaching standard lessons difficult. However, many teachers have reported that the open-ended format is useful for the students, and this has been evident in the increased mean scores $(2.00$ to 2.50$)$.

\section{Assessment for Learning}

There has also been a positive change throughout the project in the participating teachers' use of 'assessment for learning' (1.88 to 2.75). The teachers have taken up this strategy, finding the use of questions throughout lessons a useful tool for accessing what students know (rather than what they don't know) and then developing questions to push the students' understanding along. This technique has been a strong scaffolding support.

However, the use of home language has met with resistance from the teachers and was not observed in any of the videos analysed. The students speak a considerable amount of Kriol in the classroom but not in ways that were encouraged in the Boaler (2008) study of Railside. In the context of this study, it was a marginal practice. Despite efforts to encourage teachers to allow students to undertake some of the cognitive labour in their first language, they were reluctant, as one teacher commented:

I don't know what they are saying. They could be talking about anything and not doing their work. I need to be in control of what they are doing and learning.

Clearly this pedagogical aspect requires more work with teachers to allow them the confidence to release their grip on the control of dialogue and so move to allow students to speak in their home language as they negotiate meaning. 


\section{Dilemmas of Pedagogical Reform in Remote Aboriginal Contexts}

For the research team, the challenging aspect for the inclusive pedagogies relate to those areas where language is central - group work, high interactivity and reporting back. These elements of the inclusive pedagogy have been problematic for teachers and stem mainly from differences in the culture of the students and the culture of school mathematics. The scores on these elements have remained constant in the project, suggesting no gain. We have sought input from teachers to help us understand the difficulties around these pedagogies. Teachers have reported that the culture of the Kimberley communities is still strong and there are still many cultural norms that are violated with the use of these pedagogies.

Kimberley Aboriginal kinship relationships require that some students may not be able to speak or work with other students due to particular 'skin' groupings. These cultural norms are very strong. In classrooms, this means that grouping these students is not possible. Further, in the smaller communities, there are some classrooms where the numbers are so small that arranging groups where the students could be put into non-skin groups is not possible. In these small classrooms, the whole class may also be from the one family and hence reluctant to work with older/younger siblings. The dilemma for us is that group work has been shown to be a powerful tool to enhance learning, yet in this context the violation of cultural norms is so strong that it may not be a useful tool for learning.

The reporting back process was also problematic due to the cultural norms around 'showing off'. In the Kimberley culture, teachers reported that showing off how much someone knew (or did not know) was a 'shame job'. The notion of 'shame' is very strong in this region so asking students to publicly show their knowledge was not appropriate. For example, in some cases, a younger person may have known something that an older student did not know. Teachers reported that this situation would lead to a shame job for the older student, with the result that younger students were reluctant to answer for fear of publicly putting down the older student. The dilemma for the research team is that since the concept of shame is so powerful there will need to be considerable renegotiation of classroom protocols if this pedagogy is to be developed more.

Related to both of these pedagogical dimensions is the challenge of high interactivity. The teachers would pose questions to create high interactivity but the social norms of the Aboriginal students in a mainstream classroom limited its potential. The students were all very keen to answer the questions posed by the teachers but part of the role of young people in these communities is to please others. The game that was played during questions is that the students must guess what the teachers wanted. What appears to happen is that once a question is posed and answered, if the teacher does not respond with a 'correct' then the students engage in a guessing game where all sorts of responses are offered. For example, in one video-taped lesson the teacher asked a question - 'what happens when I add 5 and 3?' The students offered a wide range of responses - including 8 , but when this (along with the other responses) was 
not indicated as being correct, they kept calling out numbers. This pattern of interaction was observed across all schools and all classrooms. Interviews with teachers confirmed that this was common practice in all schools. While teachers reported their frustration with the game, they were unable to change this dynamic despite concerted attempts to do so. Further interviews with Aboriginal adults indicated that this was a part of the culture where young people learn that it is always good to please elders by being compliant, and that, in this case, compliance would be engaging in the question/answer interaction. They suggested that the students would see the questions as requiring a response and hence this would be the 'game' rather than replying with the mathematically correct answer.

These challenges to the inclusive pedagogy need to be considered carefully from the perspectives of both pedagogy and ethics. While there is a substantial literature that suggests that such practices may enhance learning, this research has been conducted in schools that are Western/Modern in their approach. The contexts for remote Aboriginal communities are vastly different in terms of cultural norms.

The research team has observed some sound changes to practice in mathematics teaching, but there is considerable work that needs to be undertaken to make such practice sustainable. In remote areas the teacher turnover is high, with most teachers staying a maximum of two years. In this project we will see a turnover of more than $50 \%$ of the teachers at the end of 2009 , thus creating a need for more professional learning opportunities for the incoming staff. This turnover and need for reformed pedagogy demands a significant input of funds to ensure that pedagogy does not return to the methods that have produced very poor results for Aboriginal learners.

\section{References}

Boaler, J. (2008) 'Promoting 'relational equity' and high mathematics achievement through an innovative mixed ability approach', British Educational Research Journal, 34 (2), 167-194.

Boaler, J. \& Staples, M. (2008) 'Creating mathematical futures through an equitable teaching approach: the case of Railside school', Teachers College Record, 110 (3), 608-645.

Boaler, J., William, D., \& Brown, M. (2000) 'Students' experiences of ability grouping - disaffection, polarisation and the construction of failure', British Educational Research Journal, 26 (5), 631-648.

Burton, L. (2004) Mathematicians as enquirers, Dordrecht: Springer.

Cobb, P., Confrey, J., diSessa, A., Lehrer, R., \& Schauble, L. (2003) 'Design experiments in educational research', Educational Researcher, 32 (1), 9-13.

Cohen, E., \& Latan, R. (Eds.) (1997) Working for equity in heterogeneous classrooms: sociological theory in practice, New York: Teachers College Press. 
Education Queensland (2001) The Queensland school longitudinal reform study, Brisbane: GoPrint.

Gamoran, A. (1992) 'Is ability grouping equitable?', Educational Leadership, $50(2), 11-17$.

Goos, M. (2005) 'A sociocultural analysis of the development of pre-service and beginning teachers' pedagogical identities as users of technology', Journal of Mathematics Teacher Education, 8 (1), 35-59.

Gray, B. (1999) 'Literacy, numeracy, attendance and health', Unicorn 25 (3), 17-30.

Harrison, C., Black, P., \& Wiliam, D. (2004) 'Teachers developing assessment for learning: Impact on student achievement', Assessment in Education, 11 (1), 49-65.

Jorgensen, R., Grootenboer, P., \& Niesche, R. (2009) 'Insights into the beliefs and practices of teachers in a remote Indigenous context', in R. Hunter, B. Bicknell, \& T. Burgess (Eds), Crossing divides, Proceedings of the 32nd conference of the Mathematics Education Research Group of Australasia, Vol. 2, 696 - 699, Sydney: MERGA.

Lamb, S. (1997) School achievement and initial education and labour market outcomes, Melbourne: ACER.

Lerman, S., \& Zevenbergen, R. (2006) 'Maths, ICT and pedagogy: An examination of equitable practice across diverse settings', in J. Novotna, H. Morova, M. Kratka, \& N. Stehlikova (Eds), Mathematics in the centre, Proceedings of the $30^{\text {th }}$ conference of the international group for the Psychology of Mathematics Education, Vol. 4, 49-56, Prague: PME.

Lingard, B., Mills, M., Hayes, D. (2006) 'Enabling and aligning assessment for learning: Some research and policy lessons from Queensland', International Studies in Sociology of Education, 16 (2), 83-103.

MCEETYA (2009) National assessment program literacy and numeracy: Achievement in reading, writing, language conventions and numeracy, Canberra: Author.

Setati, M. \& Adler, J. (2001) 'Between languages and discourses: Language practices in primary multilingual mathematics classrooms in South Africa', Educational Studies in Mathematics, 43, 243-269.

Sullivan, P., Mousley, J., \& Zevenbergen, R. (2006) 'Developing guidelines for teachers helping students experiencing difficulty in learning mathematics', inn P. Grootenboer, R. Zevenbergen \& M. Chinnappan (Eds), Identities, cultures and learning spaces, Proceedings of the 29th annual conference of the Mathematics Education Research Group of Australasia, 496-503, Sydney: MERGA.

Zevenbergen, R. (2003) 'Teachers' beliefs about teaching mathematics to students from socially-disadvantaged backgrounds: Implications for social justice', in L. Burton (Ed.), Which way social justice in mathematics education?, Westport CONN/London: Praeger. 
Zevenbergen, R. \& Lerman, S. (2008) 'Learning environments using interactive whiteboards: New learning spaces or reproduction of old technologies?', Mathematics Education Research Journal, 20 (1) 108-126.

Zevenbergen, R., \& Niesche, R. (2008) Reforming mathematics classrooms: A case of remote Indigenous education, Brisbane: Griffith Institute for Educational Research.

Zevenbergen, R., Niesche, R., Grootenboer, P. J., \& Boaler, J. (2008) 'Creating equitable practice in diverse classrooms: Developing a tool to evaluate pedagogy', in M. Goos, R. Brown, \& K. Makar (Eds), Navigating currents and charting directions, Proceedings of the 31st annual conference of the Mathematics Education Research Group of Australasia, Brisbane, Vol. 2, 637-644, Brisbane: MERGA. 
Copyright of Australian Journal of Social Issues is the property of Australian Council of Social Service and its content may not be copied or emailed to multiple sites or posted to a listserv without the copyright holder's express written permission. However, users may print, download, or email articles for individual use. 